\title{
Regulation of $\alpha$-Melanocyte-Stimulating Hormone by Testosterone Is Associated with the Onset of Atopic Dermatitis Symptoms during Exercise
}

\author{
Kumi Orita1, Yurika Yamate ${ }^{2}$, Hiromi Kobayashi ${ }^{3}$, Keiichi Hiramoto ${ }^{2 *}$ \\ ${ }^{1}$ Department of Orthopedic Surgery, Osaka City University Graduate School of Medicine, Osaka, Japan \\ ${ }^{2}$ Department of Pharmaceutical Sciences, Suzuka University of Medical Science, Suzuka, Japan \\ ${ }^{3}$ Kobayashi Dermatology Clinic, Nishinomiya, Japan \\ Email: ^hiramoto@suzuka-u.ac.jp
}

How to cite this paper: Orita, K., Yamate, Y., Kobayashi, H. and Hiramoto, K. (2020) Regulation of $\alpha$-Melanocyte-Stimulating Hormone by Testosterone Is Associated with the Onset of Atopic Dermatitis Symptoms during Exercise. Journal of Biosciences and Medicines, 8, 58-68.

https://doi.org/10.4236/jbm.2020.84005

Received: February 14, 2020

Accepted: April 7, 2020

Published: April 10, 2020

Copyright $\odot 2020$ by author(s) and Scientific Research Publishing Inc. This work is licensed under the Creative Commons Attribution International License (CC BY 4.0).

http://creativecommons.org/licenses/by/4.0/

(c) (i) Open Access

\begin{abstract}
Objective: Atopic dermatitis (AD) symptoms are altered with exercise. However, no study has investigated the association between testosterone and $\mathrm{AD}$. The aim of this study was to investigate the role of testosterone by which the strength and weakness of exercise affects the skin symptoms of AD. Methods: Specific pathogen-free (SPF) and conventional NC/Nga mice were used. NC/Nga mice spontaneously developed dermal symptoms similar to $\mathrm{AD}$ patients. Two exercises, mild $(20 \mathrm{~m} / \mathrm{min}, 60 \mathrm{~min})$ and rigorous $(25$ $\mathrm{m} / \mathrm{min}$, $90 \mathrm{~min}$ ), were carried out using a treadmill four times every alternate day. Furthermore, we administered testosterone $(0,5,50,500$, and 5000 $\mathrm{pg} /$ mice) to non-exercised conventional $\mathrm{NC} / \mathrm{Nga}$ mice. On the final day of this experiment, we analyzed the plasma levels of immunoglobulin E (IgE), interleukin (IL)-6, IL-4, IL-13, testosterone and $\alpha$-melanocyte-stimulating hormone ( $\alpha$-MSH) by ELISA kit. Results: Symptoms manifested by NC/Nga mice were strongly exacerbated upon severe exercise but were ameliorated during mild exercise. Between mild and severe exercised conventional mice, the plasma level of IgE was not changed. On administering an equivalent amount of testosterone, depending on the exercise, AD-like symptoms in non-exercising $\mathrm{NC} / \mathrm{Nga}$ mice were ameliorated with mild exercise and exacerbated through rigorous exercise. Plasma IL-6, IL-4, and IL-13 levels remained unchanged between $+50 \mathrm{pg}$ (mild) and $+500 \mathrm{pg}$ (severe) testosterone administration. Plasma $\alpha$-MSH levels were elevated with +500 pg testosterone but decreased with $+50 \mathrm{pg}$ testosterone administration. Conclusion: The present results suggest that exercise largely mimics $\mathrm{AD}$ symptoms depending on the $\alpha$-MSH and testosterone levels.
\end{abstract}




\section{Keywords}

Atopic Dermatitis, $\alpha$-Melanocyte Stimulating Hormone, Testosterone

\section{Introduction}

More than $90 \%$ of testosterone is produced by the testes from cholesterol and helps maintain muscle volume and strength. Furthermore, testosterone regulates attention and cognition [1]. However, testosterone dysregulation leads to various disorders, including metabolic syndrome, reproductive lesions, cognitive dysfunction, mood disorders, increased visceral fat, decreased muscle mass, anemia, and an isodensity [2] [3]. Lack of sleep and exercise further affects testosterone levels [4] [5]. Testosterone levels are decreased in individuals with depression [2] [3]. Upon muscle stimulation during exercise, blood testosterone levels increase [4]. Furthermore, the androgen receptor is reportedly upregulated in muscles upon muscular training [6]. Muscles bear high testosterone levels, and on interacting with the androgen receptor of muscle cells, testosterone promotes cytokinesis and increases muscle mass. However, blood testosterone levels are immediately decreased upon intense exercise [6].

Atopic dermatitis $(\mathrm{AD})$ is a disease characterized by eczematous lesions accompanied by itchiness with repeated exacerbation and remission. Furthermore, many AD patients reportedly present with atopic disposition [7]. If an AD patient perspires upon exercise, $\mathrm{AD}$ symptoms are considered to have exacerbated; however, moderate exercise reportedly benefits $\mathrm{AD}$ patients. Furthermore, on examining a mouse model of $\mathrm{AD}(\mathrm{NC} / \mathrm{Nga}$ mice), previous studies reported $\mathrm{AD}$ exacerbation with rigorous exercise and amelioration with mild exercise [8]. Upon mild exercise, levels of peptide hormones including $\alpha$-melanocyte-stimulating hormone $(\alpha-\mathrm{MSH})$ and $\beta$-endorphin synthesized through cleavage of proopiomelanocortin (POMC) in the pituitary gland may be altered, thus ameliorating $\mathrm{AD}$ [8]. However, the mechanism underlying $\mathrm{AD}$ amelioration through mild exercise remains unclear.

Hence, male hormones are affected through rigorous exercise, and AD symptoms are altered with exercise. However, no study has investigated the association between testosterone and AD. Therefore, the aim of this study was to investigate alterations in $\mathrm{AD}$ onset and its association with testosterone during exercise.

\section{Materials and Methods}

\subsection{Animals}

Conventional and specific-pathogen-free (SPF) NC/Nga male mice (8-week-old) were purchased from SLC (Hamamatsu, Shizuoka, Japan) and housed in rooms at $23^{\circ} \mathrm{C} \pm 1^{\circ} \mathrm{C}$; SPF mice, SPF conditions. These animals were handled in accor- 
dance with the animal care regulations of Osaka City University Medical Science and Suzuka University of Medical Science. All surgeries were performed on mice under pentobarbital anesthesia, and efforts were made to minimize animal suffering. Conventional mice spontaneously exhibited symptoms characteristic of $\mathrm{AD}$ at 7 weeks of age (under air-uncontrolled, conventional circumstances). As expected, all conventional NC/Nga mice used herein presented AD-like symptoms. The AD symptom score in the conventional mice was determined on the basis of the severity of dermal, erythema, and hemorrhage as previously described [9]. Furthermore, we used six groups of mice (SPF: non-, mild-, severe-exercised and conventional: non-, mild-, severe-exercised mice; $\mathrm{n}=6$ ).

\subsection{Voluntary and Exercise Protocols}

To condition animals to a device for exercise, they were placed on a resting treadmill for $10 \mathrm{~min}$, followed by running at $5 \mathrm{~m} / \mathrm{min}$ for $10 \mathrm{~min}$ and then at 10 $\mathrm{m} / \mathrm{min}$ for $10 \mathrm{~min}$. On day 2 , animals were placed on an upwards inclined device (at $10^{\circ}$ ) at a speed of $20 \mathrm{~m} / \mathrm{min}$ for $60 \mathrm{~min}$ or $25 \mathrm{~m} / \mathrm{min}$ for $90 \mathrm{~min}$ for mild or rigorous exercise, respectively [8]. These exercises were carried out every alternate day (4 times in total).

\subsection{Evaluation of the Inflammatory Score}

On day 9, $\mathrm{AD}$ symptoms in these animals were evaluated at their rostral skin, and their severity of edema, erythema, and hemorrhage was scored ( 0 , none; 1 , slight; 2, moderate; 3 , severe) as previously described [9].

\subsection{Testosterone Treatment}

We intraperitoneally administered testosterone to examine the effect of testosterone on AD. During mild exercise, we increased blood testosterone levels by 10 -fold during each exercise from 0 to $5000 \mathrm{pg} / \mathrm{mL}(0,5,50,500$, and 5000 $\mathrm{pg} / \mathrm{mL}$ ). Testosterone (Katayama, Osaka, Japan) in polyethylene glycol 400 (PG; Wako, Osaka, Japan) was intraperitoneally administered to control $(0 \mathrm{pg} / \mathrm{mL})$ mice. We injected testosterone and/or PG continuously for $7 \mathrm{~d}$, and they sampled on the experimental final day.

\subsection{ELISA for Plasma IgE, Testosterone, IL-6, IL-4, IL-13, and $\alpha$-MSH Levels}

Blood was intracardially sampled on the last day of the experiment. Plasma levels of IgE, testosterone, L-6, IL-4, IL-13, and $\alpha$-MSH were determined using a commercial ELISA kit (IgE: YamasaShoyu Co., LTD., Chiba, Japan; testosterone: Cayman chemical, Ann Arbor, MI, USA; IL-4, IL-6 and IL-13: R\&D Systems, Minneapolis, MN, USA; $\alpha$-MSH: Phoenix Pharmaceuticals Inc., Hayward, CA, USA) in accordance with the manufacturer's instructions. The optical density was measured using a micro plate reader (Molecular Devices, Sunnyvale, CA, USA). 


\subsection{Statistical Analysis}

All data are presented as the mean \pm standard deviation (SD) values. The results were analyzed using Microsoft Excel 2010 software (Microsoft Corp., Redmond, WA, USA). Differences among groups were evaluated using one-way ANOVA, followed by Turkey's post-hoc test, using SPSS version 20 software (SPSS, Inc., Chicago, IL, USA). The results were considered statistically significant if $\mathrm{p}<$ 0.05 .

\section{Results}

\subsection{Effect of Exercise on Dermatitis}

Conventional mice exhibited AD-like symptoms including edema, erythema, and hemorrhage at their rostral skin (Figure 1). Dermal symptoms were ameliorated upon mild exercise and exacerbated upon rigorous exercise. AD symptoms were not apparent in the SPF group even with rigorous exercise.

\subsection{Effect of Exercise on Plasma IgE and Testosterone Levels}

Plasma level of IgE was significantly higher than SPF mice on the conventional mice; however, no difference was observed among control, mild exercise, and severe exercise groups (Figure 2(a)). Plasma testosterone levels did not differ among these three groups and SPF mice; however, plasma testosterone levels were higher upon mild exercise and even higher upon rigorous exercise than those in control mice (Figure 2(b)). Furthermore, plasma testosterone levels in conventional mice were-control: $350 \mathrm{pg} / \mathrm{mL}$; mild exercise: $400 \mathrm{pg} / \mathrm{mL}$; and severe exercise: $850 \mathrm{pg} / \mathrm{mL}$.
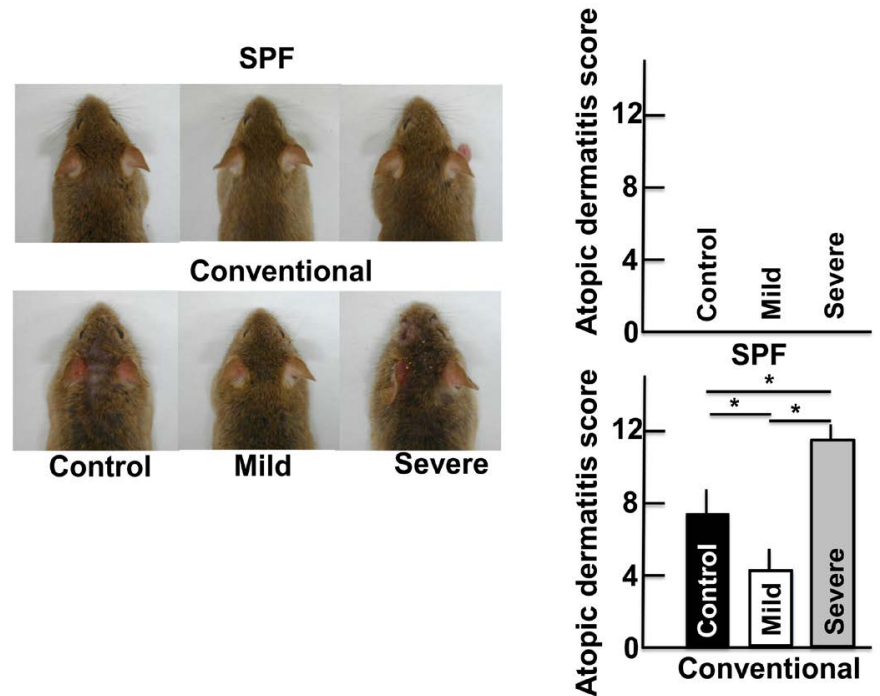

Figure 1. Atopic dermatitis (AD)-like skin lesion of conventional and specific pathogen-free (SPF) NC/Nga mice. Skin symptoms and $\mathrm{AD}$ scores after mild and rigorous exercise for four times. The data show the results obtained from six animals. The values are expressed at mean \pm standard deviation $(\mathrm{SD}) .{ }^{\star} \mathrm{P}<0.05$. 

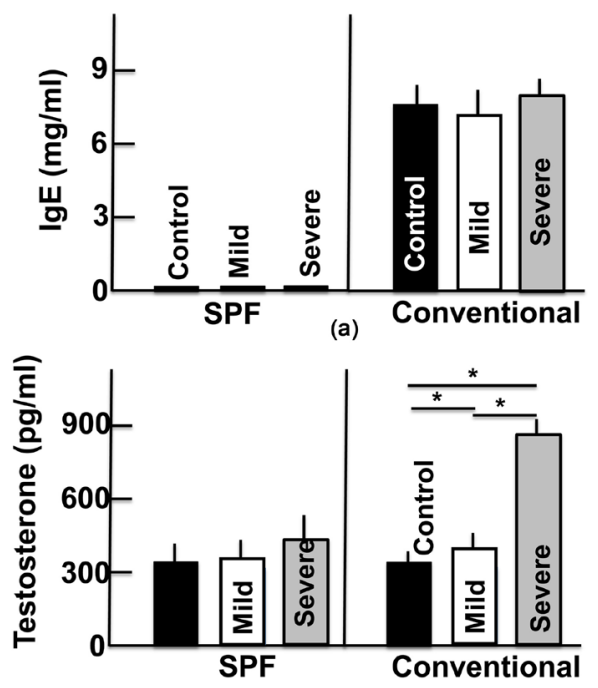

(b)

Figure 2. Plasma concentration of $\operatorname{IgE}$ (a) and testosterone (b) in specific pathogen-free (SPF) and conventional NC/Nga mice. The data show the results obtained from six animals. The plasma IgE and testosterone after mild or rigorous exercise for four times. The values are expressed at mean \pm standard deviation (SD). ${ }^{\star} \mathrm{P}<0.05$.

\subsection{Effect of Testosterone Treatment on AD}

Testosterone was administered to non-exercising NC/Nga mice to investigate its effect on $\mathrm{AD}$. In conventional mice, $\mathrm{AD}$ symptoms (erythema and edema) were ameliorated upon $50 \mathrm{pg}$ testosterone administration. The symptoms exacerbated upon administration of 500 or $5000 \mathrm{pg}$. The $5 \mathrm{pg}$ testosterone administration was not effective to atopic symptom. However, the SPF mice displayed no change upon testosterone treatment (Figure 3). The 50-pg testosterone dose was equivalent to mild exercise, and the 500-pg dose was equivalent to rigorous exercise.

\subsection{Effect of Testosterone Treatment on Plasma Levels of IgE, IL-6, IL-4, and IL-13}

Plasma IgE levels remained constant irrespective of the amount of testosterone administration in conventional mice (Figure 4(a)). Plasma levels of IL-6 indicated the value lower than un-administered mice on the testosterone $50 \mathrm{pg}$ or 500 pg administered conventional mice. Conventional mice administered 5000 pg were not different from the untreated mice (Figure 4(b)). Plasma IL-4 and IL-13 levels were lower upon administration of $\geq 50 \mathrm{pg}$ testosterone than in untreated conventional mice (Figure 4(c) and Figure 4(d)). Among SPF mice, neither of the cytokine levels changed, irrespective of the testosterone dose.

\subsection{Effect of Testosterone Treatment on Plasma $\alpha$-MSH Levels}

Plasma level of $\alpha$-MSH indicated the value lower than the non-administered 

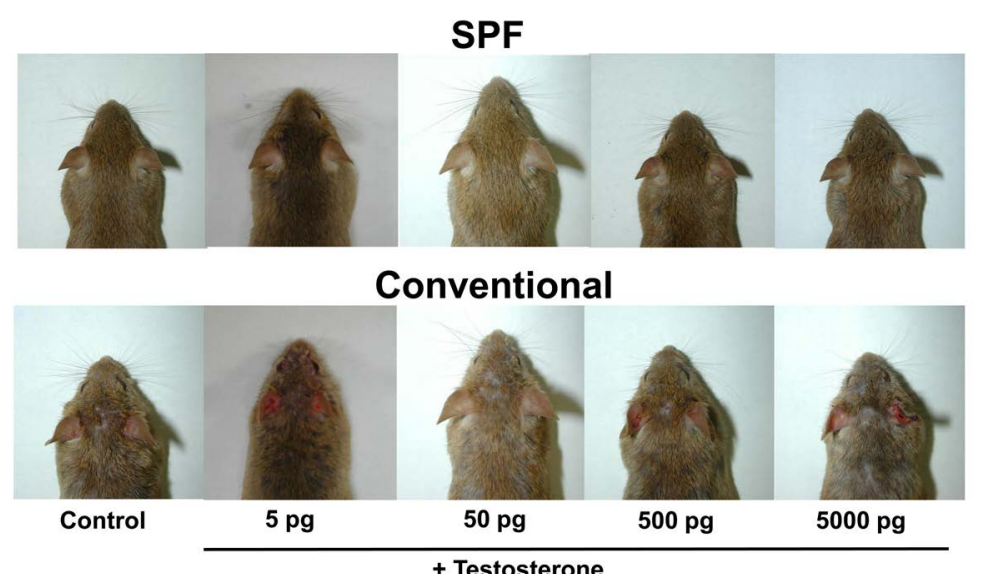

Total plasma testosterone volume $(\mathrm{pg} / \mathrm{ml})$

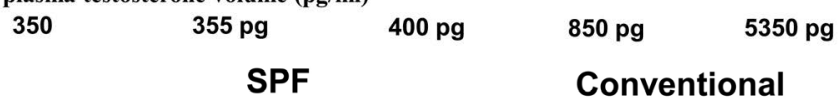

SPF

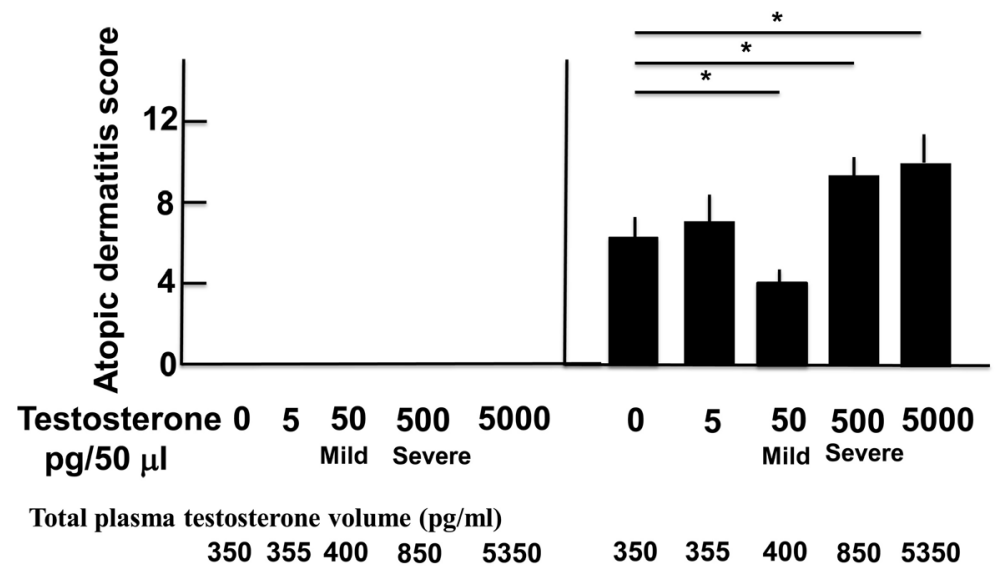

Figure 3. Atopic dermatitis (AD)-like skin lesions in conventional and specific pathogen-free (SPF) NC/Nga mice. Skin symptoms and AD scores after testosterone administration in non-exercising mice for $7 \mathrm{~d}$. $+50 \mathrm{pg}$ (total $400 \mathrm{pg})=$ testosterone value during mild exercise. $+500 \mathrm{pg}$ (total $850 \mathrm{pg})=$ testosterone value during rigorous exercise. The data show the results obtained from six animals. The values are expressed at mean \pm standard deviation $(\mathrm{SD}) .{ }^{*} \mathrm{P}<0.05$.

conventional mice by the testosterone $50 \mathrm{pg}$ administered conventional mice. However, the $\geq 500 \mathrm{pg}$ administration conventional mice increased compared with the non-administered conventional mice (Figure 5). The plasma level of $\alpha$-MSH in the 5 pg testosterone administered conventional mice was same as in non-administered conventional mice. On the SPF mice, $\alpha$-MSH level did not change irrespective of the doses of testosterone.

\section{Discussion}

This study shows that AD symptoms are ameliorated through mild exercise and exacerbated through rigorous exercise. On administering non-exercising conventional mice with each dose of testosterone, which was equivalent to mild exercise or rigorous exercise, $\mathrm{AD}$ symptoms were ameliorated after administering 
(a)

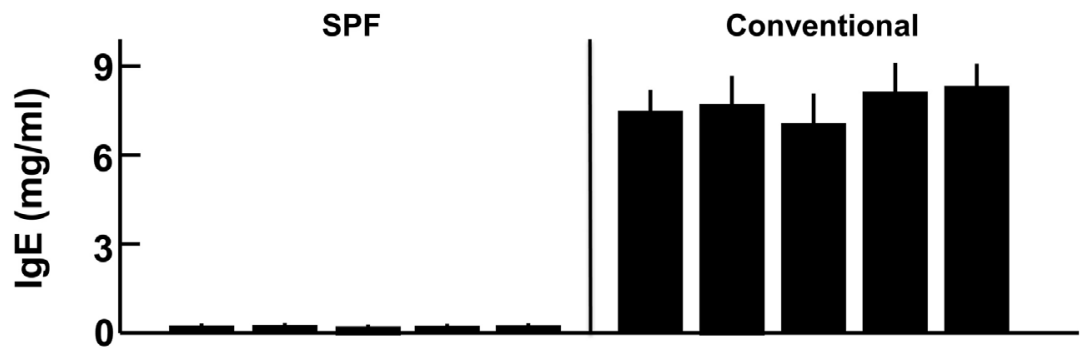

(b)

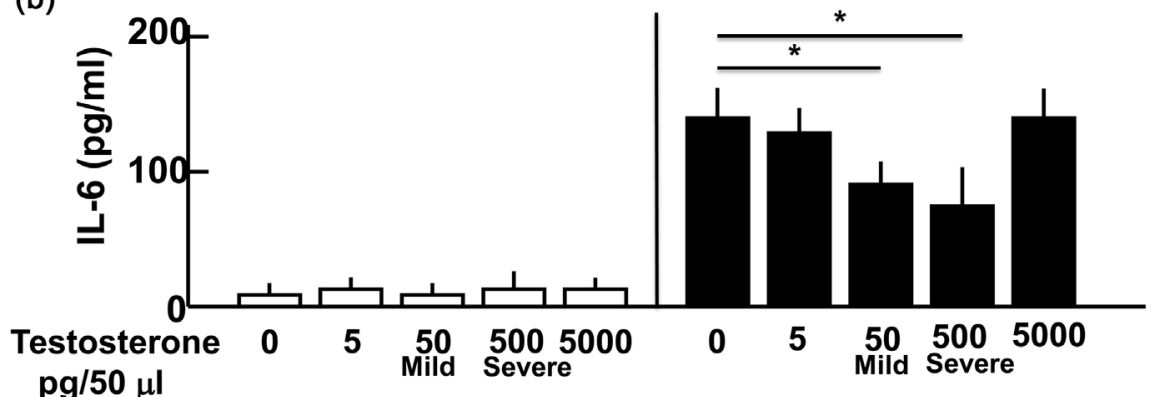

Total plasma testosterone volume $(\mathrm{pg} / \mathrm{ml})$ $\begin{array}{llllllllll}350 & 355 & 400 & 850 & 5350 & 350 & 355 & 400 & 850 & 5350\end{array}$

(c)

SPF

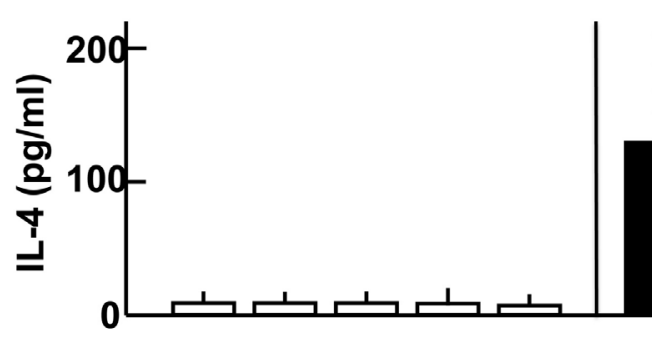

(d)

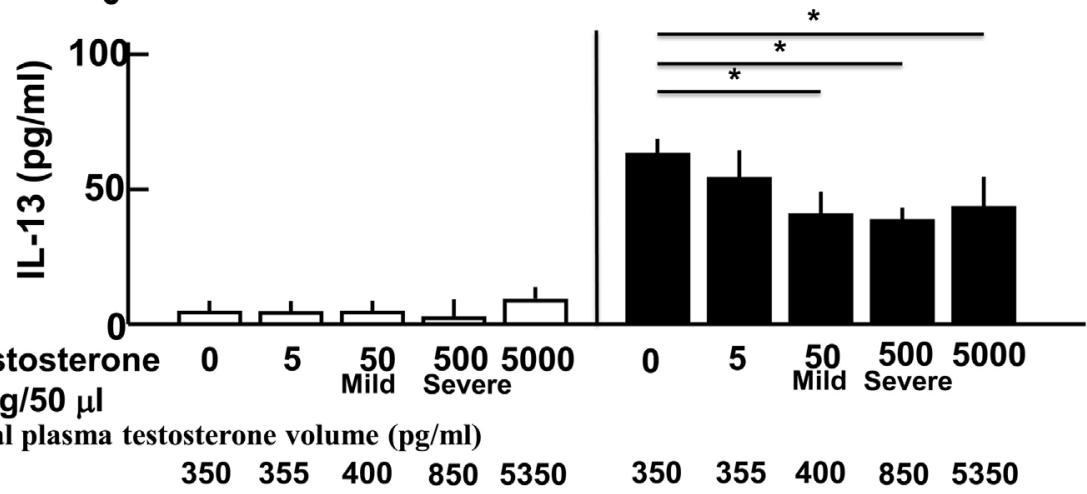

Figure 4. Plasma levels of IgE (a), IL-6 (b), IL-4 (c), and IL-13 (d) in specific pathogen-free (SPF) and conventional NC/Nga mice. Plasma levels of IgE, IL-6, IL-4, and IL-13 after testosterone administration in non-exercising mice for $7 \mathrm{~d}$. $+50 \mathrm{pg}($ total $400 \mathrm{pg})=$ testosterone value during mild exercise. $+500 \mathrm{pg}$ (total $850 \mathrm{pg}$ ) = testosterone value during rigorous exercise. The data show the results obtained from six animals. The values are expressed at mean \pm standard deviation $(\mathrm{SD}) .{ }^{*} \mathrm{P}<0.05$.

mild exercise-equivalent testosterone doses and were exacerbated upon a rigorous exercise-equivalent testosterone dose. Furthermore, blood IL-6, IL-4, and IL-13 levels in mice in the mild and rigorous exercise-equivalent testosterone groups were lower than those in non-exercising mice. However, $\alpha$-MSH levels in 


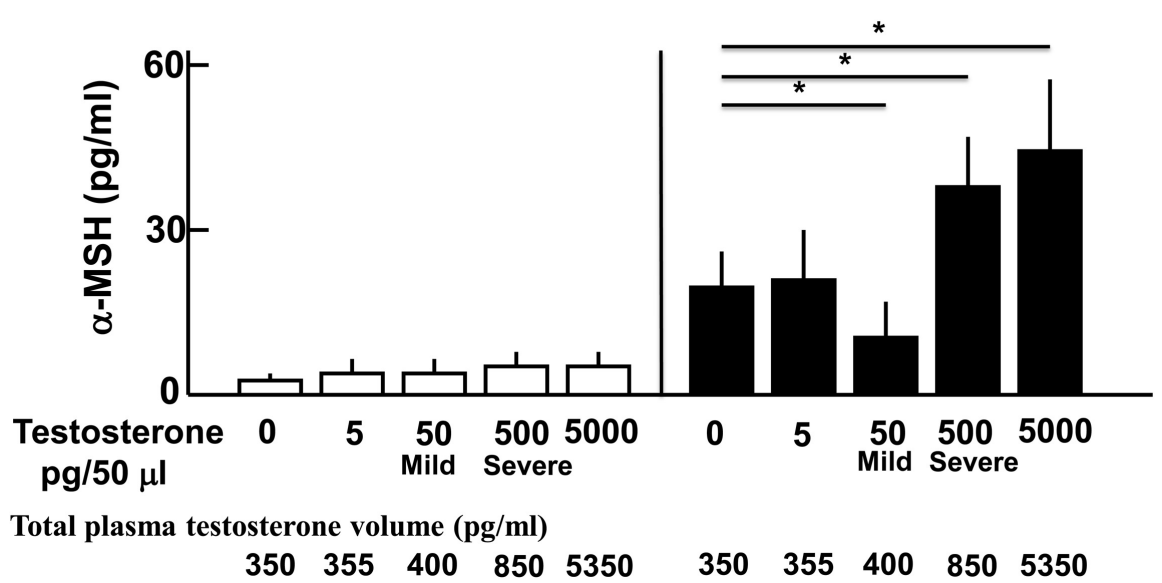

Figure 5. Plasma $\alpha$-melanocyte-stimulating hormone ( $\alpha$-MSH) levels in specific pathogen-free (SPF) and conventional NC/Nga mice. Plasma $\alpha$-MSH levels after testosterone administration in non-exercising mice for $7 \mathrm{~d}$. $+50 \mathrm{pg}$ (total $400 \mathrm{pg})=$ testosterone value during mild exercise. $+500 \mathrm{pg}$ (total $850 \mathrm{pg}$ ) = testosterone value during rigorous exercise. The data show the results obtained from six animals. The values are expressed at mean \pm standard deviation (SD). ${ }^{*} \mathrm{P}<0.05$.

blood were the lowest in mice administered a testosterone dose equivalent to mild exercise and were higher in mice administered a testosterone dose equivalent to rigorous exercise, compared to those in untreated mice.

At the time of exercise, various cytokine is produced from a skeletal muscle. Typical things are IL-6, IL-8, brain derived neurotrophic factor (BDNF) and fibroblast growth factors (FGF)21, and especially, the blood level of IL-6 remarkably increases. The increase in IL-6 reinforces systemic inflammation [10]. Testosterone has the function which inhibits inflammatory cytokine, such as IL-6. In this study, as a result of testosterone administered conventional mice with equivalent to mild or severe exercise, the IL-6 levels of both groups were decreased. From these things, it was thought that an alteration of the atopic symptom by testosterone had a few intervention of IL-6.

On the other hand, on the AD, many Th2 cells which produce IL- 4 and IL-13 gather for the nidus part of an acute stage, in the early-phase inflammation of an $\mathrm{AD}$, Th2 cell has an important role [11]. IL-4 and IL-13 which were produced from Th2 cell modulate a production of the mediator of the downstreams, such as IL-5, IL-31, and IgE [12]. And IL-4 and IL-13 inhibit expression of the filaggrin, loricrin and involucrein, and inhibit a differentiation of epidermal cells. Furthermore, IL-4 and IL-13 also inhibit production of antimicrobial peptide. From these things, IL- 4 and IL-13 are concerned in the formation and the deterioration of the skin lesion of $\mathrm{AD}$ [13] [14] [15]. In this experiment, the blood levels of IL-4 and IL-13 were decreased by testosterone administration. However, the atopic symptom was deteriorating on testosterone administration equivalent to severe exercise, and it was suggested that IL-4 and IL-13 are not directly related to the response to severe exercise. 
On the other side, the level of $\alpha$-MSH in conventional mice was decreased with mild exercise in comparison to a non-exercise control group and increased in severe exercise. On the $\alpha$-MSH, it plays key roles in exercise stress responses and immunological modulation [16] [17]. The $\alpha$-MSH observation in this study suggested that $\alpha$-MSH-induced signaling might participate in the exacerbation of the symptoms of AD. In fact, $\alpha$-MSH interacts with MC1R on a variety of leukocytes, thereby modulating inflammatory reactions induced by endotoxin and related cytokines including IL-1, TNF- $\alpha$ and INF- $\gamma$ [18] [19] [20]. $\alpha$-MSH enhances the production of TGF- $\beta$ [21]. Therefore, the TGF- $\beta$ /TGF- $\beta$-receptor signaling pathway might activate POMC system to increase plasma levels of $\alpha-\mathrm{MSH}$, thereby exacerbating the symptoms of AD. In this experiment, $\alpha-\mathrm{MSH}$ considered the same alternation as testosterone. This was considered that testosterone acted on the $\alpha$-MSH secretion system (constructional system), fluctuated the amount of $\alpha$-MSH, and has affected the atopic symptom. Also another report, the increase in immunoreactivity of $\alpha$-MSH and MC1R is reported under existence of testosterone [22]. However, there are a few reports which indicated the relation between testosterone and $\alpha-\mathrm{MSH}$, and the mechanism from which testosterone induces the increase in $\alpha-\mathrm{MSH}$ is not known. The further examination will be necessary in the future.

Moreover, the difference in the amount of testosterone in blood was observed by the strength of exercise. Although there is a paper in which it was indicated that an alteration occurs to the amount of testosterone with quantity of motion similarly [23] [24], the detailed mechanism is not known. What kind of factor of exercise is concerned in testosterone, or the further examination is necessary.

However, in this study, we used mice in vivo experiment, then we should have clinical study in human to the future.

\section{Conclusion}

This study shows the effects of different levels of exercise on AD. Mild exercise without physical stress suppressed AD exacerbation. Reductions in $\alpha$-MSH levels were accompanied by the suppression of $\mathrm{AD}$ symptoms. This study provides novel insights into the value of continuous mild exercise to prevent lifestyle-related diseases and $\mathrm{AD}$, thus promoting an active lifestyle.

\section{Acknowledgements}

This study was supported by JSPS KAKENHI (Grant Number 18K11085). We would like to thank Editage (www.editage.com) for English language editing.

\section{Conflicts of Interest}

The authors have no conflict of interest to declare.

\section{Funding}

This study was supported by JSPS KAKENHI (Grant Number 18K11085). 


\section{References}

[1] Coates, J.M. and Herbert, J. (2008) Endogenous Steroids and Financial Risk Taking on a London Trading Floor. Proceedings National Academy of Sciences USA, 105, 6162-6172. https://doi.org/10.1073/pnas.0704025105

[2] Muller, M., Grobbee, D.E., den Tonkelaar, I., Lamberts, S.W. and van der Schouw, Y.T. (2005) Endogenous Sex Hormones and Metabolic Syndrome in Aging Men. Journal Clinical Endocrinology \& Metabolism, 90, 2618-2623. https://doi.org/10.1210/jc.2004-1158

[3] Eskelinen, S.I., Vahlberg, T.J., Isoaho, R.E., Kivela, S.L. and Irjala, K.M. (2007) Associations of Sex Hormone Concentrations with Health and Life Satisfaction in Elderly Men. Endocrine Practice, 13, 743-749. https://doi.org/10.4158/EP.13.7.743

[4] Zmuda, J.M., Thompson, P.D. and Winters, S.J. (1996) Exercise Increases Serum Testosterone and Sex Hormone-Binding Globulin Levels in Older Men. Metabolism, 45, 935-939. https://doi.org/10.1016/S0026-0495(96)90258-9

[5] Schmid, S.M., Hallschmis, M., Jauch-Chara, K., Lehnert, H. and Schultes, B. (2012) Sleep Timing May Modulate the Effect of Sleep Loss on Testosterone. Clinical Endocrinology (Oxford), 77, 749-754. https://doi.org/10.1111/j.1365-2265.2012.04419.x

[6] Poole, C.N., Roberts, M.D., Dalbo, V.J., Sunderland, K.L. and Kerksick, C.M. (2011) Megalin and Androgen Receptor Gene Expression in Young and Old Human Skeletal Muscle before and after Three Sequential Exercise Bouts. Journal of Strength and Conditioning Research, 25, 309-317. https://doi.org/10.1519/JSC.0b013e318202e45d

[7] Kato, N., Saeki, H., Nakahara, T., Tanaka, A., Kabashima, K., Sugaya, M., Murota, H., Ebihara, Z., Kataoka, Y., Aihara, M. and Eto, T. (2016) Atopic Dermatitis Clinical Practice Guideline 2016. Japanese Journal of Dermatoligy, 126, 121-155.

[8] Orita, K., Hiramoto, K., Inoue, R., Sato, E.F., Kobayashi, H., Ishii, M. and Inoue, M. (2010) Strong Exercise Stress Exacerbates Dermatitis in Atopic Model Mice, NC/Nga Mice, While Proper Exercise Reduces It. Experimental Dermatology, 19, 1067-1072. https://doi.org/10.1111/j.1600-0625.2010.01130.x

[9] Dahten, A., Koch, C., Ernst, D., Schnoller, C., Hartmann, S. and Worm, M. (2008) Systemic PPAR Ligation Inhibits Allergic Immune Response in the Skin. Journal of Investigative Dermatology, 128, 2211-2218. https://doi.org/10.1038/jid.2008.84

[10] Celli, B.R., Locantore, N., Yates, J., Tal-Singer, R., Miller, B.E., Bakke, P., Calverley, P., Coxson, H., Crim, C., Edwards, L.D., Lomas, D.A., Duvoix, A., MacNee, W., Rennard, S., Silverman, E., Vestbo, J., Wouters, E., Agusti, A. and ECLIPSE Investigators (2012) Inflammatory Biomarkers Improve Clinical Prediction of Mortality in Chronic Obstructive Pulmonary Disease. American Journal of Respiratory and Critical Care Medicine, 185, 1065-1072. https://doi.org/10.1164/rccm.201110-1792OC

[11] Vangipuram, R. and Tyring, S.K. (2017) Dupilumab for Moderate-to-Severe Atopic Dermatitis. Skin Therapy Letter, 22, 1-4.

[12] Bantz, S.K., Zhu, Z. and Zheng, T. (2014) The Atopic March: Progression from Atopic Dermatitis to Allergic Rhinitis and Asthma. Journal of Clinical and Cellular Immunology, 5, 202.

[13] Novak, N. and Leung, D.Y. (2011) Advances in Atopic Dermatitis. Current Opinion in Immunology, 23, 778-783. https://doi.org/10.1016/j.coi.2011.09.007

[14] Malajian, D. and Guttman-Yassky, E. (2015) New Pathogenic and Therapeutic Pa- 
radigms in Atopic Dermatitis. Cytokine, 73, 311-318.

https://doi.org/10.1016/j.cyto.2014.11.023

[15] Leung, D.Y. and Guttman-Yassky, E. (2014) Deciphering the Complexities of Atopic Dermatitis: Shifting Paradigms in Treatment Approaches. Journal of Allergy and Clinical Immunology, 134, 769-779. https://doi.org/10.1016/j.jaci.2014.08.008

[16] Flint, M.S., Morgan, J.B., Shreve, S.N. and Tinkle, S.S. (2003) Restraint Stress and Corticotropin Releasing Hormone Modulation of Murine Cutaneous POMC mRNA. Stress, 6, 59-62. https://doi.org/10.1080/1025389031000088426

[17] Blalock, J.E. (1999) Proopiomelanocortin and the Immune-Neuroendocrine Connection. Annals of the New York Academy of Sciences, 885, 161-172. https://doi.org/10.1111/j.1749-6632.1999.tb08673.x

[18] Ichiyama, T., Sakai, T., Catania, A., Barsh, G.S., Furukawa, S. and Lipton, J.M. (1999) Systemically Administered-Melanocyte-Stimulating Peptides Inhibit NF-B Activation in Experimental Brain Inflammation. Brain Research, 836, 31-37. https://doi.org/10.1016/S0006-8993(99)01584-X

[19] Rajora, N., Ceriani, G., Catania, A., Star, R.A., Murphy, M.T. and Lipton, J.M. (1996) Alpha-MSH Production, Receptors, and Influence on Neopterin in a Human Monocyte/Macrophage Cell Line. Journal of Leukocyte Biology, 59, 248-253. https://doi.org/10.1002/jlb.59.2.248

[20] Lipton, J.M. and Catania, A. (1997) Anti-Inflammatory Actions of the Neuroimmunomodulator-MSH. Immunology Today, 18, 140-145. https://doi.org/10.1016/S0167-5699(97)01009-8

[21] Namba, K., Kitaichi, N., Nishida, T. and Taylor, A.W. (2002) Induction of Regulatory $\mathrm{T}$ Cells by the Immunomodulating Cytokines Alpha-Melanocyte-Stimulating Hormone and Transforming Growth Factor-beta2. Journal of Leukocyte Biology, 72, 946-952.

[22] Whang, S.W., Lee, S.E., Kim, J.M., Kim, H.J., Jeong, S.K., Zouboulis, C.C., Seo, J.T. and Lee, S.H. (2011) Effects of Melanocyte-Stimulating Hormone on Calcium Concentration in SZ95 Sebocytes. Experimental Dermatology, 20, 19-23. https://doi.org/10.1111/j.1600-0625.2010.01199.x

[23] Kraemer, W.J. and Ratamess, N.A. (2005) Hormonal Responses and Adaptations to Resistance Exercise and Training. Sports Medicine, 35, 339-361. https://doi.org/10.2165/00007256-200535040-00004

[24] Viru, A., Kareison, K. and Smirnova, T. (1992) Stability and Variability in Hormonal Responses to Prolonged Exercise. International Journal of Sports Medicine, 13, 230-235. https://doi.org/10.1055/s-2007-1021259 